\title{
Gegenhalten von Führungsdrähten
}

\author{
Dankward Höntzsch, Alexander Motzny
}

Für die Marknagelung und bei kanülierten Schrauben wird über Führungsdrähten gebohrt.

Beim Zurückführen des Bohrers sollte der Führungsdraht in seiner guten Position verbleiben und nicht mit zurückgezogen werden. Für die Führungsdrähte bei der Marknagelung gibt es dazu ausgeklügelte Zangen oder andere Gegenhalter. Oder es werden normale Zangen und/oder Klemmen verwendet.

Die speziellen Geräte sind oft kompliziert, Klemmen gehen kaputt.

Ein Nachteil ist, dass mit Zangen und Klemmen 1 bis $2 \mathrm{~cm}$ verschenkt werden, wenn die kanülierte Bohrmaschine die Zange oder Klemme erreicht.

Eine einfache und bequeme Alternative ist, einfach einen scharfen Löffel zu verwenden ( $\triangleright$ Abb. 1). Nicht wegen des scharfen Randes, sondern wegen der Kuhle, mit welcher der Draht zentriert gegengehalten werden kann ( $\triangleright$ Abb. 1). Es können auch andere Löffel verwendet werden. Aber mit einem scharfen Löffel ist das Vorgehen sehr elegant und sicher ( $\bullet$ Abb. $\mathbf{1}$ und $\mathbf{2}$ ).

Das Instrument ist im OP allgegenwärtig und preiswert.

Man gewinnt die Strecke zwischen Zangenposition und dem Ende ( $\bullet$ Abb. 2).

Die Methode ist einfacher und verbraucht weniger Handgriffe als das Zupacken und Lösen der Zange oder Klemme.

Korrespondenzadresse

\section{Dankward Höntzsch}

Tübingen

hoentzsch@t-online.de

\section{Alexander Motzny}

BG Unfallklinik Tübingen

amotzny@bgu-tuebingen.de

\section{Bibliografie}

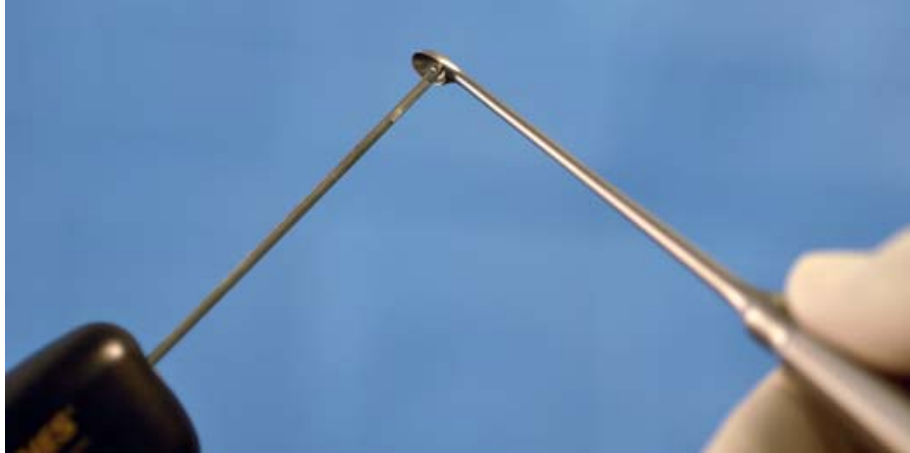

Abb. 1 Das Ende des Führungsdrahtes wird in der Kuhle des scharfen Löffels sicher zentriert gehalten.

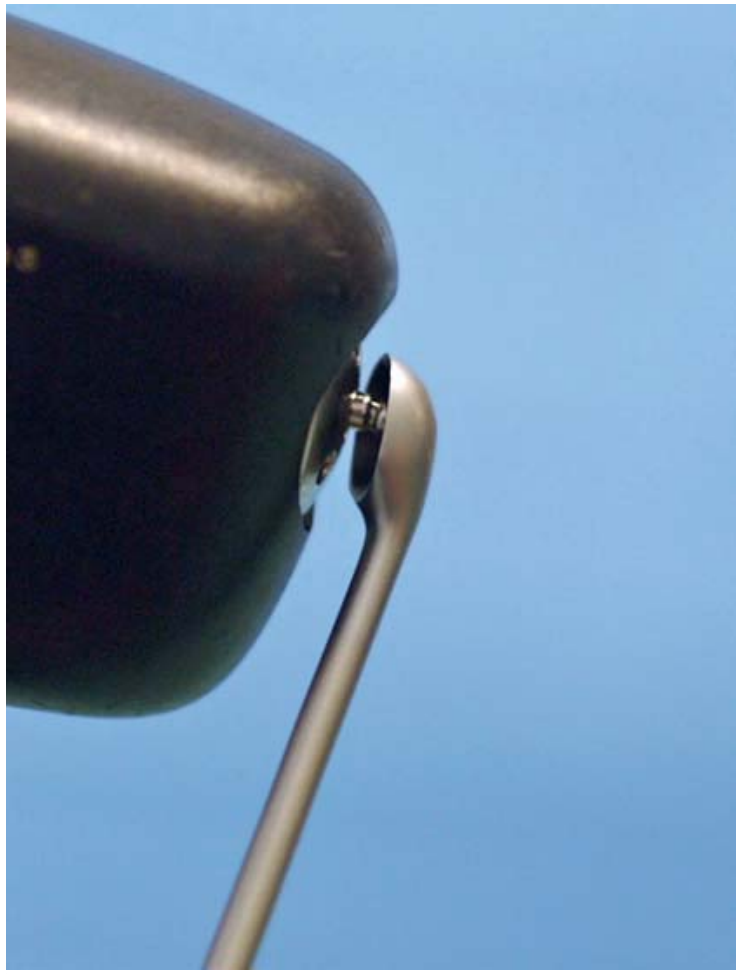

Abb. 2 Man kann bis zum letzten Millimeter gegenhalten. 